\title{
A comparative study of sampling techniques for monitoring carcass contamination
}

\author{
J.M.A. Snijders, M.H.W. Janssen, G.E. Gerats and G.P. Corstiaensen \\ Department of the Science of Food of Animal Origin. Faculty of Veterinary Medicine. University of Lirecht. \\ P.O. Box 80175,3508 TD Utrecht. The Netherlands
}

(Received 22 April 1984; accepted 22 October 1984)

\begin{abstract}
Four bacteriological sampling techniques i.e. the excision. double swab. agar contact and modified agar contact techniques were compared by sampling pig carcasses before and after chilling. As well as assessing the advantages and disadvantages of the techniques particular attention was paid to variation due to the effects of chilling. The agar contact technique cannot be used for determining the contamination of carcasses because 100 many plates became overcrowded with micro-organisms. Results obtained by the double swab and modified agar technique gave standard deviations which were significantly higher than those of the excision technique. This may indicate a superior repeatability of the excision technique. Statistical analysis of the results showed that chilling influenced the differences between sampling techniques. The excision technique is to be regarded as the most suitable in view of its high accuracy and precision. When the technique is used properly. carcass damage is only small or negligible.
\end{abstract}

Key words: Carcass contamination: Microbiological monitoring

\section{Introduction}

Good manufacturing practice (GMP) during slaughter. as described in the Recommended International Code of Hygienic Practice for Fresh Meat, includes all necessary measures to produce meat with the lowest possible microbial contamination. This is attainable only if the whole process is strictly controlled (World Health Organization, 1983).

Sampling of carcass surfaces for microbiological examination should be used to identify critical points in slaughterlines (Gerats et al., 1981). Data thus obtained may be used in monitoring the process in order to attain a good end-product.

Sampling techniques have to be accurate and precise to make valid microbiological comparisons of different steps in slaughterlines. Accuracy is defined as: the closeness of agreement between the true value and the mean result obtained by applying the experimental procedure a very large number of times; precision as: the closeness of agreement between the results obtained by applying the experimental procedure several times under prescribed conditions (International Organization for Standardization (ISO), 1977). Small systematic errors resulting in lower levels of accuracy may be accepted only on the condition that they do not substantially affect precision. 
Various techniques have been suggested for determining bacterial colony count on carcasses. Those commonly used are the agar contact technique, the swab technique and the excision technique.

In the agar contact technique an appropriate agar surface is pressed on to the test area and then incubated. A number of advantages of this method have been listed: simplicity and rapidity, low costs and the possibility of 'visualization' of microbiological data (ten Cate, 1963; Terbijhe, 1976). Disadvantages are low accuracy and precision, confluent growth and overcrowding of plates at relatively low levels of contamination (Kampelmacher et al., 1971; Niskanen and Pohja, 1977). Furthermore, high levels of contamination will substantially hamper quantitative readings or even make them impossible. Moreover, the method is restricted to smooth and flat surfaces.

A modified technique, developed by Silliker et al. (1957) involves homogenization of impressed agar slices in peptone saline solution whereupon colony counts are made by the conventional poured plate method (Nortje et al., 1982).

The swab technique relies on rubbing one or two (the so-called double swab technique') swabs on a test surface, after which the swabs are transferred to a dilution bottle, shaken, diluted and aliquots plated onto an appropriate medium. Using this technique not only meat and carcass surfaces, but also wooden. tiled and metal surfaces can be monitored.

The main objection to this method is the relatively low and irreproducible recovery of bacterial cells (Mossel and Büchli, 1964; Lazarus et al., 1977; Emswiller et al., 1978). Attempts to improve the consistency of results by standardization of the swab technique have mostly failed (Favero et al., 1968; Kampelmacher et al.. 1971; Baldock, 1974). The nature of the sampled surface plays an important part in recovery. Both Lahellec and Colin (1979) and Sauter et al. (1979) obtained significantly lower yields when examining dry carcass surfaces by the swab technique. Marshall et al. (1977) found that different populations may be obtained when colonizing organisms are removed by the use of a swab as compared to excision. Whereas swabbing removes only a variable proportion of the organisms in the water film on the surface, excision releases all cells from a given area including the ones attached to the surface (Notermans et al., 1979; Firstenberg-Eden, 1981).

In the excision technique, pieces of tissue are removed and homogenized in a peptone saline solution (Dockerty et al., 1970; Snijders, 1976). The excision technique produces reliable results, provided maceration is adequate (Gerats and Snijders, 1978). The recovery obtained with the excision technique is higher than with swab and agar contact techniques (Sibomana, 1980; Nortje et al., 1982; Lillard and Thomson, 1983). Disadvantages of the excision technique include restriction of the sampling technique to small areas, the time required, and damage caused to the carcass surfaces (Patterson, 1968; Ingram and Roberts, 1976; Emswiller et al., 1978).

Comparison of different sampling techniques is usually made under standardized laboratory conditions or at one stage in a production line only. Little notice has been taken of the ecological changes occurring on carcass surfaces as a consequence of cooling, drying or shrinking during processing.

The purpose of this study was to test, under practical conditions, four sampling 
techniques, i.e. excision, swab, agar contact and a modified agar contact technique. Chilled carcasses were also sampled since chilling might affect the results of the sampling methods under investigation.

\section{Materials and Methods}

The experiment was performed at a pig slaughterhouse. The hot pig carcass. weight varied from $90-100 \mathrm{~kg}$. After electrical stunning the pigs were bled. scalded for 5-6 min at $60^{\circ} \mathrm{C}$, and subsequently singed after which the carcasses were polished in a black-scraping machine. Earlier investigations (Snijders, 1976: Gerats et al., 1981) revealed that a significant and evenly distributed increase of the contamination on carcass surfaces occurred during black scraping. Because an increase of contamination is likely to occur during evisceration and meat inspection. only backs of carcasses which had not been manipulated nor touched by tools, water and slaughter equipment. were sampled.

During 3 sampling days 15 carcasses were sampled. The backs of these carcasses were divided into 4 sites. At each site areas of $15 \mathrm{~cm}^{2}$ were sampled by the four sampling techniques described below. Samples were taken from the freshly slaughtered pigs and after two days of chilling at $3 \pm 1{ }^{\circ} \mathrm{C}$.

\section{Sampling techniques}

Excision technique: From each sampling site three tissue discs were removed using sterile cork borers (diameter $2.52 \mathrm{~cm}$ ). scalpels and tweezers. Samples were collected in sterile plastic bags. The combined surface area sampled was $15 \mathrm{~cm}^{2}$.

$45 \mathrm{ml}$ of peptone saline solution (PS) were added after which samples were macerated in a stomacher (Colworth 400 ) for $2 \mathrm{~min}$. Suitable aliquots were plated on media described below.

Double swab technique: Surface areas of $15 \mathrm{~cm}^{2}$ were marked with a sterile template and sampled with a cotton wool swab moistened in PS and subsequently with a dry swab. The swabs were held in sterile forceps and the meat surface was swabbed ten times from top to bottom applying a firm pressure on the surface. Both swabs were collected in the same bottle which contained $45 \mathrm{ml}$ PS. The bottle was shaken vigorously for 2 min before diluting and plating.

Agar contact technique: Two small plastic dishes (so called Steri Keri plates, Lamaf. Groningen) filled with $4.5 \mathrm{ml}$ plate count agar (PCA) and two dishes filled with violet red bile glucose agar (VRBG) were pressed on to each site and subsequently incubated. The contact surface of each plate was $7.5 \mathrm{~cm}^{2}$.

Modified agar contact technique: Sampling procedures were similar to those described for the agar contact technique. After sampling, the contents of the agar dishes were removed aseptically and homogenized in a sterile plastic bag with $36 \mathrm{ml}$ PS. Thus, after homogenizing for $2 \mathrm{~min}$ in a Colworth stomacher, $45 \mathrm{ml}$ diluent was available for plating. 


\section{Bacteriological procedures}

In total 60 samples from freshly slaughtered pigs and 60 from chilled carcasses were obtained with each sampling technique. The following values were determined: (1) aerobic colony count (ACC) on PCA (Oxoid CM 463) (poured plate method incubation at $30^{\circ} \mathrm{C}$ for 3 days) (International Organization for Standardization (ISO), 1976); (2) The Enterobacteriaceae colony count (ECC) on violet red bile glucose agar (Oxoid CM 485) (poured plate method with overlay, incubation at $37^{\circ} \mathrm{C}$ for 1 day) (International Organization for Standardization (ISO), 1979).

Colony forming units (CFU) per $\mathrm{cm}^{2}$ were transformed into logarithms to the base 10 and a statistical analysis was carried out separately with the results from each sampling technique. Means of the results of excision, double swab and modified agar contact technique were compared, using Student $t$ tests. Moreover, a three factor analysis of variance was performed on the results of these sampling techniques to test interactions and overall effects of different sampling sites, different sampling days and chilling.

Since accurate counting per $\mathrm{cm}^{2}$ was not possible with the agar contact technique data obtained were grouped in the following classes (van Schothorst et al., 1966): Class 1: less than $10 \mathrm{CFU}$; class 2: 10-29 CFU; class 3: 30-89 CFU and class 4: $\geqq 90 \mathrm{CFU}$. Each class was assigned colony counts corresponding with the counts assessed by means of the excision technique.

\section{Results}

A consistently higher recovery both for ACC and ECC was observed with the excision technique (Table I) as compared with the swab and modified agar contact techniques $(P<0.01)$.

\section{TABLE I}

The effect of sampling techniques on assessment of surface contamination of hot and chilled carcasses $(n=60)$.

\begin{tabular}{|c|c|c|c|c|}
\hline \multirow[t]{2}{*}{$\begin{array}{l}\text { Sampling } \\
\text { technique }\end{array}$} & \multicolumn{2}{|c|}{$\begin{array}{l}\text { Aerobic colony counts } \\
\left(\log _{10} \text { per } \mathrm{cm}^{2}\right)\end{array}$} & \multicolumn{2}{|c|}{$\begin{array}{l}\text { Enterobacteriaceae colony counts } \\
\left(\log _{10} \text { per } \mathrm{cm}^{2}\right)\end{array}$} \\
\hline & $\begin{array}{l}\text { Hot } \\
\text { carcasses }\end{array}$ & $\begin{array}{l}\text { Chilled } \\
\text { carcasses }\end{array}$ & $\begin{array}{l}\text { Hot } \\
\text { carcasses }\end{array}$ & $\begin{array}{l}\text { Chilled } \\
\text { carcasses }\end{array}$ \\
\hline Excision & $3.66 \pm 0.43^{\mathrm{a}}$ & $3.82 \pm 0.30$ & $1.42 \pm 0.49(85)^{b}$ & $1.63 \pm 0.53(97)$ \\
\hline Swab & $3.23 \pm 0.66$ & $3.12 \pm 0.59$ & $0.86 \pm 0.37(48)$ & $1.12 \pm 0.44(62)$ \\
\hline $\begin{array}{c}\text { Modified } \\
\text { agar } \\
\text { contact }\end{array}$ & $1.79 \pm 0.65$ & $2.66 \pm 0.49$ & $0.70 \pm 0.33(13)$ & $1.14 \pm 0.55(55)$ \\
\hline
\end{tabular}

- Standard deviation.

b Figures in parentheses indicate the percentage of plates suitable for colony counting $(\log \mathrm{CFU} \geqq 0.48$ ). 
The standard deviation of the results for ACC as assessed by the double swab and modified agar technique were significantly higher than the standard deviation of the excision technique. This may indicate a superior repeatability of the excision technique. Comparison of standard deviations for ECC can hardly be made. due to the low percentage of plates suitable for colony counting i.e. $\log C F U \geqq 0.48$.

After two days chilling the ACC and ECC as assessed by the excision technique increased significantly $(P<0.02)$, while a small though insignificant decrease of ACC was observed with the swab technique. However the swab technique revealed a significant $(P<0.01)$ increase of ECC. The mean value of ACC and ECC obtained with the modified agar contact technique increased significantly $(P<0.01)$ after chilling.

The correlation coefficients between the swab and modified agar contact technique and the excision technique for the ACC (Table II) were relatively low. Correlation coefficients of the results within techniques before and after chilling were considerably lower in the double swab and modified agar contact technique as compared with the excision technique.

With the excision technique, significant differences in counts were observed between the three sampling days $(P<0.001)$ and also as a consequence of the chilling regime $(P<0.05)$. These differences were not detected by the double swab technique $(P>0.05)$. However, the double swab technique revealed interactions

\section{TABLE II}

Correlation between sampling techniques with regard to the excision technique and within sampling techniques before and after chilling of the carcasses

\begin{tabular}{|c|c|c|c|}
\hline \multirow{2}{*}{$\begin{array}{l}\text { Sampling } \\
\text { technique }\end{array}$} & \multicolumn{2}{|c|}{ Between techniques } & \multirow{2}{*}{$\begin{array}{l}\text { Within techniques } \\
\text { Before and after chilling }\end{array}$} \\
\hline & Hot carcass & Chilled carcass & \\
\hline Excision & - & - & 0.65 \\
\hline Swab & 0.34 & 0.39 & 0.44 \\
\hline $\begin{array}{l}\text { Modified agar } \\
\text { contact }\end{array}$ & 0.35 & 0.31 & 0.20 \\
\hline
\end{tabular}

TABLE III

Analysis of variance of two factors affecting aerobic colony counts on the surface of pig carcasses.

\begin{tabular}{lrrrrl}
\hline Source & \multicolumn{1}{c}{ SS $^{2}$} & $\mathrm{dF}^{\mathrm{b}}$ & $\mathrm{MS}^{\mathrm{c}}$ & $F_{\text {ratio }}$ & $P$ \\
\hline Sampling techniques & 146.41 & 2 & 73.20 & 246.81 & $<0.001$ \\
Chilling & 8.70 & 1 & 8.70 & 29.33 & $<0.001$ \\
Interaction & 15.83 & 2 & 7.91 & 26.68 & $<0.001$ \\
Error & 105.00 & 354 & 0.30 & & \\
$\quad$ & & & & \\
$\quad$ Total & 275.94 & 359 & & & \\
\hline
\end{tabular}

a Sum of squares.

b Degrees of freedom.

c Mean square. 
between sampling days and sites.

With the modified agar contact technique differences between sampling days were not the same for all sites. Moreover, an interaction between sampling days and chilling was found. These effects were not confirmed by the results obtained by the excision technique.

Table III shows the results of an analysis of variance, testing the effect of three sampling techniques (excision, swab and modified agar contact technique) and of chilling. The results show a clear interaction between sampling technique and chilling, which means that changes in the carcass surface following chilling clearly affect the results of the different sampling techniques.

Table IV shows the results of the agar contact technique, as compared with the results of the excision technique. As expected, most samples fell into classes 3 and 4 . It is impossible to assess the actual level of carcass contamination using the agar contact technique, since there is no significant difference between the mean values of the corresponding samples belonging to classes 3 and 4 obtained with the excision technique. Classification of the ACC is generally difficult because the majority of plates obtained from chilled samples were found to be overcrowded. Even when the level of contamination is low, the results are not reliable.

High ECCs do not correspond to a higher classification, nor do low values to a lower classification. $63 \%$ of the samples with an ECC $>\log 2$ were grouped into the lowest classes, while $23 \%$ of the samples below $\log 2$ fell into the highest classes.

\section{Discussion}

In agreement with results in the literature, the highest colony counts were obtained by the excision technique. In this technique, both loosely and firmly

\section{TABLE IV}

A comparison of assessment of aerobic colony counts and Enterobacteriaceae colony counts on pig carcasses by the agar contact technique (ACT) and the excision technique (ET).

\begin{tabular}{|c|c|c|c|c|c|c|}
\hline & & Class $1^{a}$ & Class 2 & Class 3 & Class 4 & \\
\hline \multicolumn{7}{|c|}{ Aerobic colony counts } \\
\hline \multirow[t]{2}{*}{ Hot carcasses } & $\mathrm{ACT}^{\mathrm{b}}$ & 2 & 1 & 27 & 30 & . \\
\hline & $\mathrm{ET}^{\mathrm{c}}$ & 3.33 & 3.11 & 3.58 & 3.77 & \\
\hline \multirow[t]{2}{*}{ Chilled carcasses } & $\mathrm{ACT}$ & & & 4 & 56 & \\
\hline & ET & & & 3.86 & 3.81 & \\
\hline \multicolumn{7}{|c|}{ Enterobacteriaceae colony counts } \\
\hline \multirow[t]{2}{*}{ Hot carcasses } & ACT & 55 & 4 & & & \\
\hline & ET & $1.37(84)^{d}$ & 1.51 & & & \\
\hline \multirow[t]{2}{*}{ Chilled carcasses } & ACT & 29 & 15 & 13 & 3 & \\
\hline & ET & $1.48(93)$ & 1.70 & 1.78 & 2.09 & \\
\hline
\end{tabular}

Class-intervals (CFU/dishes): $1:<10 ; 2: 10-29 ; 3: 30-89 ; 4: \geqq 90$.

b Number of samples per class.

c Mean $\log _{10}$ CFU per $\mathrm{cm}^{2}$ of the corresponding samples belonging to that class.

d Figures in parenthesis indicate percentage of plates suitable for colony counting $(\log \mathrm{CFU} \geqq 0.48$ ). 
attached organisms will be released whereas by the other techniques mainly loosely adhered bacteria will be recovered. Nortje et al. (1982) claim that, provided the differences or correlations between an excision technique and other techniques are known, these techniques may also be used.

Our study, however, demonstrates that the differences between sampling techniques may vary, as a consequence of technological treatments (e.g. chilling) of the carcass. Especially in performing HACCP analyses for hygienic quality assurance in slaughterlines, the results of sampling techniques should not be affected by these treatments.

With the excision technique no significant differences were observed between the four sites on a carcass. This indicates that the prerequisites for such investigations. viz (i) an evenly distributed microflora on the carcass surfaces as a result of the black-scraping procedure; and (ii) avoiding recontamination by careful slaughtering. had indeed been achieved. The excision technique revealed significant differences between sampling days, indicating irregularities in the daily cleaning and disinfection procedures of the black-scraper. The double swab technique, showing no significant differences between sampling days failed to demonstrate this phenomenon. Moreover, the influence of chilling was not assessed appropriately using the double swab technique. The double swab technique used in this investigation relies on the use of a wet and a dry swab, producing better results than just sampling with one swab (Patterson, 1971). To minimize the problem of variables in the swabbing technique, such as pressure, rubbing time and moistening of the swab (Favero et al. 1968; Baldock, 1974), all swabbing experiments were carried out by the same person. Therefore the method was not tested for reproducibility. As emphasized before, in practice it is very difficult to standardize a swab technique, making results of different investigations difficult to compare.

The agar contact technique is also less appropriate for determining the contamination on carcasses because too many plates are usually overcrowded. Even at low surface colony counts the recovery by this method is very low (Table IV). The application of this method should therefore be restricted to smooth and flat surfaces. especially with low rates of contamination.

The modified agar contact technique, which is principally based on the same method as the agar contact technique is also not appropriate for assessing the contamination of carcasses.

\section{References}

Baldock, J.D., 1974. Microbiological monitoring of the food plant: methods to assess bacterial contamination of surfaces. J. Milk Food Technol. 37, 361-368.

Dockerty, T.R., H.W. Ockerman, V.R. Cahill, L.E. Kunkle and H.H. Weiser, 1970. Microbial level of pork skin as affected by the dressing process. J. Animal Sci. 30. 884-890.

Emswiller. B.S.. J.E.Nichols, A.W. Kotula and D.K. Rough. 1978. Device for microbiological sampling of meat surfaces. J. Food Prot. 41, 546-548.

Favero. M.S., J.J. McDade, J.A. Robertsen, R.K. Hoffman and R.W. Edwards. 1968. Microbiological sampling of surfaces. J. Appl. Bacteriol. 31, 336-343. 
Firstenberg-Eden, R., 1981. Attachment of bacteria to meat surfaces: A review. J. Food Prot. 44, $602-607$.

Gerats, G.E. and J.M.A. Snijders, 1978. Bestimmung von Keimzahlen in der Fleischindustrie. III. Das Stomacher verfahren und das Spiralplattenverfahren. Arch. Lebensm. Hyg. 29, 57-61.

Gerats, G.E., J.M.A. Snijders, J.G. van Logtestijn, 1981. Slaughter techniques and bacterial contamination of pig carcasses. Proc. 27th Eur. Meet. Meat Res. Work., Vienna. 198-200.

Ingram, M. and T.A. Roberts, 1976. Recent advances in hygiene of meat production. R. Soc. Health J. 96, 270-276.

International Organization for Standardization, 1976. International Standard ISO 2293 Meat and meat products - Aerobic count at $30^{\circ} \mathrm{C}$. (Reference-method) 1st ed. 1976-04-01.

International Organization for Standardization, 1977. International Standard ISO 3534 Statistics-Vocabulary and symbols 1st edn. 1977-07-01.

International Organization for Standardization, 1979. International Standard ISO 5552 Meat and meat products. Detection and enumeration of Enterobacteriaceae (Reference methods) 1st edn. 1979-04-01.

Kampelmacher, E.H., D.A.A. Mossel, M. van Schothorst and L.M. van Noorle Jansen, 1971. Quantitative Untersuchungen über die Dekontamination von Holzflächen in der Fleischverarbeitung. Alimenta Sondernr.70-76.

Lahellec, C. and P. Colin, 1979. Bacterial flora of poultry: Changes due to variations in ecological conditions during processing and storage. Arch. Lebensm. Hyg. 30, 95-98.

Lazarus, C.R., A. Abu-Babar, R.L. West and J.L. Oblinger, 1977. Comparison of microbial counts on beef carcasses by using the moist-swab, contact method and secondary tissue removal technique. Appl. Environm. Microbiol. 33, 217-218.

Lillard, H.S. and J.E. Thomson, 1983. Comparison of sampling methods for Escherichia coli and total aerobic counts on broiler carcasses. J. Food Prot. 46, 781-782.

Marshall, R.T., M.E. Anderson, H.D. Naumann and W.C. Stringer, 1977. Experiments in sanitizing beef with sodium hypochlorite. J. Food Prot. 40, 246-249.

Mossel, D.A.A. and K. Büchli, 1964. The Total Object Swab (T.O.S.) technique. Lab. Pract. 13, 1184-1187.

Niskanen, A. and M.S. Pohja, 1977. Comparitive studies on the sampling and investigation of microbial contamination of surfaces by the contact plate and swab methods. J. Appl. Bacteriol. 42, 53-63.

Nortje, G.L., E. Swanepoel, R.T. Naude, W.H. Holzapfel and P.L. Steyn, 1982. Evaluation of three carcass surface microbial sampling techniques. J. Food Prot. 45, 1016-1017.

Notermans, S.W.H., R. van Firstenberg-Eden and M. van Schothorst, 1979. Attachment of bacteria to the teats of cows. J. Food Prot. 42, 228-232.

Patterson, J.T., 1968. Hygiene in meat processing plants: two methods of assessing carcass contamination. Rec. Agric. Res. 17, 1-5.

Patterson, J.T., 1971. Microbiological assessment of surfaces. J. Food Technol. 6. 63-72.

Sauter, E.A., J.A. Jacobs, J.F. Parkinson and S.K.Ercanbrach, 1979. Effect of carcass weight and fat thickness of lamb carcasses on surface bacteria counts. J. Food Sci., 44, 1430-1434.

Schothorst, M. van, D.A.A. Mossel and E.H. Kampelmacher, 1966. Stufenkontrollen mit Agarwürsten nach ten Cate. Arch. Lebensm. Hyg. 17, 1-4.

Sibomana, G., 1980. Vergleichende Untersuchungen über die Brauchbarkeit von Probenentnahmeverfahren zur Oberflächenkeimzahlbestimmung bei Schlachttierkörpern. Inaug. Dissertation, Berlin.

Silliker, J.H., H.P. Andrews and J.F. Murphy, 1957. A new non-destructive method for the bacteriological sampling of meat. Food Technol. 11, 317-319.

Snijders, J.M.A., 1976. Pig slaughtering hygiene. Thesis. Faculty of Veterinary Medicine, The University of Utrecht.

ten Cate, I., 1963. Eine einfache und schnelle bakteriologische Kontrolle in fleischverarbeitenden Betrieben mittels Agar-"Würsten" in Rilsan-Kunstdarm, Fleischwirtschaft 43, 483-487.

Terbijhe, R.J. 1976. Effect van reiniging van desinfectie in pluimveeslachterijen. Tijdschr. Diergeneesk. 101, 190-194.

World Health Organisation, 1983. Guidelines on prevention and control of Salmonellosis. Document V.P.H. $/ 83.42$. 